\title{
ESTADO ACTUAL DEL CARCINOMA IN SITU DEL CUELLO UTERINO, EN EL HOSPITAL SAN JUAN DE DIOS DE BOGOTA
}

\author{
Dr. Alvaro Fonnegra Miramón* \\ Dr. Carlos E. Sarria Olcos**
}

\begin{abstract}
TRABAJO PRESENTADO AL VI CONGRESO DE OBSTETRICIA Y GINECOLOGIA EN CARTAGENA, POR LA SECCION DE OBSTETRICIA Y GINECOLOGIA DE LA FACULTAD DE MEDICINA DE LA UNIVERSIDAD NACIONAL DE COLOMBIA
\end{abstract}

Se hace una revisión de 34 casos de $\mathrm{Ca}$. in situ diagnosticados, tratados y controlados en el servicio de Ginecología en el Hospital San Juan de Dios de Bogotá.

En este Servicio como norma de conducta, una vez diagnosticado el Ca. pre-invasor por biopsia, se procede a practicar conización del cuello uterino para descartar por cortes seriados el carcinoma invasor. Ya con el resultado anatomopatológico de la conización se decide el próximo paso a seguir, que puede ser histerectomía - control de la paciente con citologías periódicas.

La decisión del procedimiento es dada por las condiciones propias de cada paciente, como edad, paridad, facilidad para controlar, patología genital asociada etc.

Todas las pacientes histerectomizadas o no, son sometidas a controles clínicos y citológicos luego de la intervención con intervalo de tres me-

* Profesor Asociado.

** Residente de cuarto año. Sección de Obstetricia y Ginecología. ses durante el primer año y en caso de ser éstos negativos, se sigue controlando cada seis meses.

Consideramos los resultados obtenidos en estas 34 pacientes, como un gran adelanto en la pesquisa y diagnóstico precoz del cáncer, pues en 25 de ellas, el diagnóstico fue hallazgo del examen citológico, hecho de rutina a toda paciente que consulta al servicio de ginecología, y confirmado luego con biopsia.

\section{MATERIAL Y METODOS}

Se incluyen en este trabajo los casos de $\mathrm{Ca}$. in situ diagnosticados y tratados desde Diciembre de 1962.

La citología vaginal rutinaria se ha hecho desde Diciembre de 1963 y hasta el momento se han practicado aproximadamente cinco mil exámenes.

Antes de establecerse este procedimiento como rutina, se practicaron 500 citologías en casos escogidos encontrándose 5 casos de Ca. in situ.

En las 5.500 citologías rutinarias se encontraron 46 casos positivos pa- 
ra Ca. intraepitelial, de los cuales 12 no recibieron tratamiento por ausencia de las pacientes, a pesar del empeño por localizarlas, siendo tratadas 34, que son el objeto del presente trabajo.

En todos los casos aquí revisados se anotó edad, paridad, causa de consulta, estado macroscópico del cuello, citología y biopsia del cérvix al ingreso, tratamiento recibido, anatomía patológica de las piezas quirúrgicas, complicaciones post-operatorias y controles periódicos luego de intervenidas. A cada uno de estos datos nos referimos a continuación.

\section{EDAD}

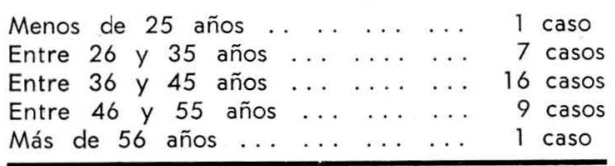

Corresponde la mayor incidencia al grupo comprendido entre 36 y 45 años $(47 \%)$. Este dato corroborado por algunos autores señalan la edad media de la vida, como la que mayor incidencia tiene de Ca. intraepitelial.

\section{PARIDAD}

\begin{tabular}{llllllll} 
Nulíparas & $\ldots$ & $\ldots$ & $\ldots$ & $\ldots$ & $\ldots$ & $\ldots$ & 1 caso \\
Primíparas & $\ldots$ & $\ldots$ & $\ldots$ &. & $\ldots$ & $\ldots$ & 3 casos \\
Multiparas & $\ldots$ & $\ldots$ & $\ldots$ & $\ldots$ & $\ldots$ & $\ldots$ & 30 casos \\
\hline
\end{tabular}

Al igual que el carcinoma invasor, el $\mathrm{Ca}$. in situ presenta gran tendencia a incidir en multíparas ( $88 \%)$ ).

CAUSA dE CONSULta

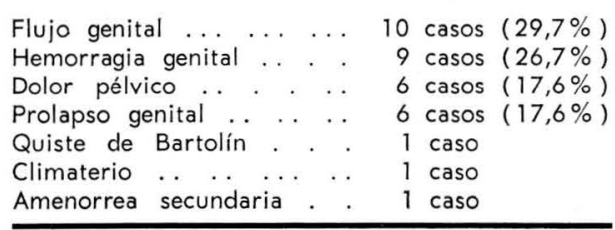

Este cuadro es tal vez el más diciente de este estudio, pues en él se ven a las claras varios hechos importantísimos. De los 34 casos, en 25 de ellos $(74,4 \%)$ la sintomatología que obligó a consultar, no tenía ninguna relación con la entidad diagnosticada (Ca. in situ). Los 9 casos restantes fueron consultas por hemorragia genital, discriminadas así: metrorragias 7 casos e hipermenorreas 2 . Solo una de ellas presentaba también hemorragia post-coito. De lo anterior se reafirma que el carcinoma intraepitelial es asintomático, y que su diagnóstico siempre debe ser buscado de rutina para obtener éxito en el tratamiento.

Otro hecho importante es la relación cáncer prolapso, 6 c a sos $(17,6 \%)$, demuestran una incidencia mucho más alta que la observada con el carcinoma invasor $(1,4 \%)$; muchas ulceraciones por prolapso genital, pasan por alto por creerse que son inherentes a aquél y que con la cirugía se extirpan sin mayores consecuencias. Queremos insistir en el estudio anatomopatológico de las ulceraciones por prolapso genital pues en ocasiones presenta patología maligna.

Estado del cuello. Muy relacionado con lo anterior, llama la atención que en 14 casos $(41,2 \%)$, a la especuloscopia el cuello NO presentaba ninguna alteración macroscópica y que el hallazgo citológico de malignidad que puso sobre el diagnóstico de carcinoma fue además una sorpresa.

Cuello sano ... ... ... 14 casos $(41,2 \%)$
Cuello con erosión . . . 20 casos $(58,8 \%)$

CITOLOGIAS

\begin{tabular}{lllllll}
$A-3$ & $\ldots$ & $\ldots$ & $\ldots$ & $\ldots$ & $\ldots$ & $2 \operatorname{casos}(5.9 \%)$ \\
$A-4$ & $\ldots$ & $\ldots$ &. & $\ldots$ & $\ldots$ & $14 \operatorname{casos}(41,2 \%)$ \\
$A-5$ & $\ldots$ & $\ldots$ & $\ldots$ & $\ldots$ & $\ldots$ & 16 casos $(47,0 \%)$ \\
Extraviadas & $\ldots$ & $\ldots$ &. & $\ldots$ & 2 casos $.5,9 \%)$ \\
\hline
\end{tabular}


El tema de Citología es motivo de comentario especial en otro tema libre de este Congreso.

Biopsia de cérvix. Con el diagnóstico citológico de malignidad en el frotis vaginal se tomó biopsia de cérvix a las pacientes. Es de anotar que en 25 de los 34 casos no había sospecha de malignidad y que la citología fue el procedimiento que puso sobre la pista del proceso maligno.

Los resultados de las biopsias fueron los siguientes:

Positivas para Ca. in situ . 30 casos $(88,2 \%)$ Dudosas ... ....... . 4 casos $(11,8 \%)$

Los cuatro casos reportados como dudosos, fueron de metaplasia escamosa atípica, cervicitis sospechosas, en los cuales el patólogo con muy buen criterio nos recomendó la conización. En todos estos casos se comprobó $\mathrm{Ca}$. in situ.

Tratamiento. Las 34 pacientes fueron tratadas, así:

Como primer paso de tratamiento se hicieron 32 conizaciones. A 2 pacientes no se les practicó conización, procedimiento que consideramos indispensable para confirmar el diagnóstico de carcinoma in situ y descartar con alto porcentaje de seguridad la presencia concomitante de un carcinoma invasor. La causa de omisión deliberada fue en un caso la presencia de enfermedad pélvica inflamatoria sub-aguda ya tratada, que pudiera agudizarse con la conización.

En el otro caso, por error que somos los primeros en criticar, se omitió por razones del estado general de la paciente, comprobándose el diagnóstico de $\mathrm{Ca}$. intraepitelial en la pieza quirúrgica.

De las 32 conizaciones, 8 de ellas fueron tratamiento pues se trataba de pacientes jóvenes con pocos hijos y con facilidades para controlar. Las otras 24 fueron conizaciones diagnósticas que se complementaron con la histerectomía, como a continuación se especifica:

\section{TRATAMIENTO COMPLEMENTARIO}

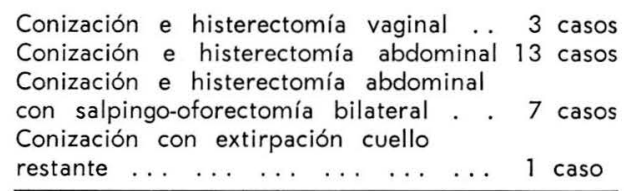

Por error diagnóstico se practicó conización en una paciente embarazada, sin que hubieran complicaciones en la evolución de su embarazo. En todas las pacientes, menos en la anterior se practicó de rutina y durante el mismo acto quirúrgico, raspado uterino para descartar patología endometrial.

Una de las complicaciones post-operatorias de la conización fue una paciente que presentó hemorragia abundante que obligó a intervenirla, esta vez por vía alta, y hacer extirpación de cuello restante, detalle pasado por alto en el examen de ingreso, pues la paciente había sido sometida a histerectomía sub-total y el operador no tuvo en cuenta la ausencia de cuerpo uterino.

Otra complicación post-operatoria fue un caso de hematometra, luego de la conización que se resolvió favorablemente con dilatación instrumental del cuello uterino.

Para la histerectomía se eligió como vía, la vaginal en 3 casos de prolapso. Las demás fueron por vía abdominal dando las complicaciones usuales de esta intervención. Se presentaron 2 abscesos de cúpula y 3 abscesos de pared.

Como detalle importante anotamos que en todas las histerectomías extir- 
pamos buena cantidad de vagina. La cirugía sobre anexos era determinada por la patología que éstos presentaran.

Piezas quirúrgicas. El estudio de las piezas quirúrgicas fue como sigue:

32 conizaciones, 30 positivas para $\mathrm{Ca}$. in situ, 2 negativas para tumor.

25 úteros, todos negativos para tumor residual.

Se interpreta la negatividad en 2 conizaciones como extirpación del $\mathrm{Ca}$. in situ en las biopsias. A estas pacientes no se les sometió a ningún otro tratamiento.

Controles. De las 34 pacientes intervenidas, 6 no volvieron a control. Con esta dificultad siempre hemos tropezado a pesar de haberles insistido a las pacientes, la necesidad que se controlaran periódicamente. En las 28 pacientes que volvieron a nuestra Clínica de Tumores, consulta especializada para control de cualquier tumor maligno genital tratado, hay controles que van, desde 2 hasta 24 meses.

Solamente un caso controlado ha tenido citología positiva ( $A-4)$, con ulceración vaginal cuya biopsia dió dudosa para carcinoma. Desafortunadamente la paciente no volvió.

Los otros controles han sido de citología negativa. En dos casos ha habido zonas vaginales sospechosas que la biopsia ha reportado como "tejido de granulación". Los controles de citología han sido reiteradamente negativos. Los controles han sido, así:

\section{CONTROLES}

Controladas menos de 6 meses ...

8 casos

Controladas entre 6-12 meses.

11 casos

Controladas entre $0-12$ meses

9 casos

\section{COMENTARIOS Y CONCLUSIONES}

1) Se hace un estudio de 34 casos de $\mathrm{Ca}$. in situ diagnosticados, tratados y controlados en el servicio de Ginecología del Hospital San Juan de Dios de Bogotá.

2) En él se hace hincapié sobre la utilidad de la citología rutinaria hecha entre nosotros descle Diciembre de 1963.

3 ) De las 34 pacientes, en 25 de ellas el diagnóstico de $\mathrm{Ca}$. intraepitelial, fue hallazgo y sorpresa, pues la causa de consulta era de prolapso genital, dolor pélvico, flujo etc.

4) La asociación Ca. in situ con prolapso genital es relativamente frecuente $(17,6 \%)$. De ahí la importancia del estudio de cualquier anomalía de cuello uterino en prolapso genital.

5) El estado sano del cuello uterino no descarta la presencia de un Ca. pre-invasor, pues en este estudio $41,2 \%$ tenían cuello macroscópicamente sano.

6) La citología vaginal debe siempre complementarse con biopsia de cuello para confirmar el diagnóstico.

7) A los dos procedimientos anteriores debe agregarse de manera imprescindible la conización para descartar el $\mathrm{Ca}$. invasor.

8) Luego de confirmación por la conización de $\mathrm{Ca}$. in situ, según las condiciones de la paciente, se define la posibilidad de histerectomía o no.

9) Cualquiera que sea el tratamiento, los controles citológicos en el post-operatorio tardío deben ser estrictos, cada 3 meses durante el primer año y luego cada 6 meses.

10) Todos nuestros controles a excepción de uno que fué dudoso, fue- 
ron negativos y continúan siéndolo en los controles actuales.

11) Con estos procedimientos creemos que sí se está haciendo la verdadera profilaxis y pesquisa del cáncer de cuello uterino, en sus primeros estadios, que es cuando se tiene seguridad de éxito en el tratamiento.

12) Por los resultados obtenidos y aquí expuestos, consideramos pleno éxito en la forma de tratamiento y manejo de estas pacientes.

\section{BIBLIOGRAFIA}

1 ANGEL GILBERTO. Estado actual del carcinoma de cuello uterino. Rev. Col. Obs. ; Gin. Vol. XV N: $133: 431964$.

2 CARDONA PEDRO N. Diagnóstico precoz del cáncer uterino por medio de la citología. Rev. Col. Obs. y Gin. C. Vol. 10 N $5 \quad 327: 338 \quad 1959$.

3 DARNALT E. JORDAN G. Ca. Intraepitelial. Memorias del II Congreso de Obstetricia y Ginecología. Cali Col.

4 ISAZA GUSTAVO. Análisis de 1.063 extendidos colpocitológicos. Rev. Col. Obs. y Gin. Vol. XI № $5 \quad 437: 4391960$.

5 LOPEZ GUILLERMO. Lesiones distróficas y Ca. in situ del cervix. Rev. Col. Obs. y Gin. Vol. 8 № 51957.

6 LOPEZ GUILLERMO. Carcinoma intraepitelial del cérvix uterino. Rev. Col. Obs. y Gin. Vol. 9 № 4 333:360 1958.
7 LOPEZ GUILLERMO. Diagnóstico precoz del cáncer. (Citología y cáncer intraepitelial) Repertorio de Medicina y Cirugía. Hosp. San Juan de Dios. Vol. 4 Ni 5 291:296 1959.

8 POSADA MARIO-VASQUEZ G. Citología exfoliativa del carcinoma de cuello uterino. Rev. Col. Obs. y Gin. Vol. 11 № 4 376: 380. 1960.

9 DIPAOLA GUILLERMO. Pesquisa de los estadios iniciales del carcinoma cervical. Rev. Col. Obs. y Gin. Vol. 14 N: $1 \quad 13: 20$ 1963.

10 MORICARD R. Reflexións sur la definition du stade $O$. des epitheliomas du col uterin. Bull de la Fed. Societes de Gynec. et d'obstetrique. Vol. 4 No $5 \quad 844: 853 \quad 1952$.

11 MEIGS J., STURGIS S .Progresos de Ginecología. 128 sig. 1958.

12 NOVAK E., JONES G. Tratado de Ginecología. 219 sig. 1962.

13 OKAGAKI T. col. Diagnosis of anaplasia and C. I. S. by differential cell counts. Acta Citológica 6. 343 sig. 1962.

14 VILLALBA RAFAEL. Diagnóstico del carcino$\mathrm{ma}$ in situ del cuello uterino. Rev. Obs. Y Gin. Venezuela 535:551 1964.

15 YOUNGE P. A. Premalignant lesions of the cervix and clinical management Clin. Obs. \& Gyn. 51.137 sig. 1962.

16 YOUNGE P. A. Cancer of the uterine cervix. A preventable disease Obst. \& Gyn. Vol. 10469 sig. 1957.

\section{CONGRESO INTERNACIONAL DE CITOLOGIA}

\section{Organizado por la Academia Internacional de Citología}

con el concurso de la Sociedad Americana de Citología, y Sociedad Brasileña de Citología.

Este Congreso se llevará a cabo en la ciudad de Río de Janeiro del 19 al 22 de Mayo de 1968

\section{Tendrá lugar en el HOTEL COPACABANA PALACE}

Las informaciones deben solicitarse a la Secretaría de la Comisión Organizadora:

Emilio Berla 47, Apto. 302

COPACABANA - RIO DE JANEIRO

Presidente: CLARICE A. FERREIRA 